\title{
CAPTOPRIL-INDUCED GLUTAMATE RELEASE AT THE START OF REPERFUSION AFTER COLD CARDIOPLEGIC STORAGE OF PIG HEARTS
}

Flemming Randsbaek, MD

Hans-Henrik Kimose, MD, PhD

Thomas Bjerre, BS

Ulla Møldrup, MD

Hans Erik Bøtker, MD, PhD

Torsten Toftegaard Nielsen, MD, DMSc
Objective: We sought to evaluate the effects of captopril on glucose-related metabolism during hypothermic cardioplegic storage and subsequent reperfusion.

Methods: We compared hearts from control pigs with hearts from pigs treated with increasing oral doses of captopril for 3 weeks (12.5-150 mg daily), an intravenous bolus ( $25 \mathrm{mg}$ ) before operation, and captopril-containing cardioplegic solution $(1 \mathrm{mg} / \mathrm{L})$. The hearts were excised after infusion of cold crystalloid cardioplegic solution and stored in saline solution $\left(4^{\circ} \mathrm{C}-6^{\circ} \mathrm{C}\right)$. In one series we studied myocardial blood flow and arteriovenous differences in oxygen, glucose, lactate, glutamate, and alanine during 60 minutes of postcardioplegic blood reperfusion. In this series captopril-treated hearts were reperfused with captopril-containing blood $(1 \mathrm{mg} / \mathrm{L})$. In another series we obtained biopsy specimens from the left ventricle throughout 30 hours of hypothermic cardioplegic storage and monitored tissue content of energyrich phosphates, glycogen, glutamate, and alanine.

Results: Captopril increased glutamate and alanine release 11- to 17-fold at the start of reperfusion $(P<.001)$. Furthermore, captopril increased myocardial oxygen and glucose uptake during reperfusion $(P<.001$ for both), whereas lactate release and myocardial blood flow were unaffected by captopril. At the start of reperfusion, there was a positive correlation between glutamate release and glucose uptake in captopril-treated hearts $(r=0.66, P$ $=.05)$. We found no statistically significant differences between captopril and control hearts in tissue content of adenosine triphosphate, glycogen, glutamate, alanine, or lactate during 30 hours of cardioplegic storage.

Conclusions: The metabolic effects of captopril are strictly related to reperfusion, during which oxidative metabolism of glucose is improved. The captopril-induced increase in glutamate and alanine release at the start of reperfusion after cardioplegic storage may reflect a switch in metabolism of glucose-related amino acids. (J Thorac Cardiovasc Surg 2000;119:1030-8)
$A^{\prime}$ ngiotensin-converting enzyme (ACE) inhibition improves the cardioprotective properties of cardioplegic solutions, resulting in improved myocardial function during postcardioplegic reperfusion. ${ }^{1,2}$ It has been proposed that the underlying mechanism may involve modulation of myocardial oxygen consump-

From the Department of Cardiology and Institute of Experimental Clinical Research, Skejby Hospital, Aarhus University Hospitals, University of Aarhus, Denmark.

Supported by the Danish Health Research Council, grant No. 9600822 (Aarhus University, Novo Nordisk Centre for Research in Growth and Regeneration).

Received for publication June 30, 1999; revisions requested Sept 16, 1999; revisions received Nov 8, 1999; accepted for publication Dec 6, 1999. tion $^{3,4}$ and glucose metabolism. ${ }^{5}$ In accordance with this, we have recently shown that captopril improves oxygen and glucose extraction during blood reperfusion of isolated pig hearts. ${ }^{6}$ It remains unknown, however, whether the beneficial effect of ACE inhibition takes place during cardioplegic storage, during reperfusion,

\footnotetext{
Address for reprints: Flemming Randsbæk, MD, Department of Cardiology, Skejby Hospital, Aarhus University Hospitals, Brendstrupgaardvej, 8200 Aarhus N, Denmark.

Copyright @ 2000 by The American Association for Thoracic Surgery

$0022-5223 / 2000 \$ 12.00+0 \quad \mathbf{1 2} / \mathbf{1} / \mathbf{1 0 4 8 6 7}$

doi:10.1067/mtc. 2000.104867
} 
or both. Furthermore, the metabolic pathways involved are not fully elucidated. Glutamate is closely related to glucose metabolism during ischemia, ${ }^{7,8}$ and improved oxidative metabolism may thus affect myocardial handling of glutamate.

We studied whether captopril affects myocardial metabolism during cardioplegic storage, postcardioplegic reperfusion, or both. We hypothesized that captopril may affect glucose-related amino acid metabolism during cardioplegic storage, postcardioplegic reperfusion, or both.

\section{Materials and methods}

Animal preparation. We used hearts from 34 domestic pigs (Danish and Yorkshire Landrace) of both sexes (heart weight, $0.35 \pm 0.02 \mathrm{~kg}$ ). The study was approved and found to be in accordance with Danish standards for the care and use of laboratory animals and animal care and procedures conformed to the guidelines established by the US National Institutes of Health (Guide for the Care and Use of Laboratory Animals; National Institutes of Health publication No. 85-23, revised 1985).

The animals were premedicated with intramuscular midazolam (Dormicum, $0.5 \mathrm{mg} / \mathrm{kg}$ ) and ketamine (Ketalar, 10 $\mathrm{mg} / \mathrm{kg}$ ) followed by intravenous ketamine $(5 \mathrm{mg} / \mathrm{kg}$ ) before orotracheal intubation. Pigs were anaesthetized with halothane $1 \%$ to $2 \%$ and placed on positive-pressure ventilation $\left(\mathrm{N}_{2} \mathrm{O} / \mathrm{O}_{2}\right.$ mixture 2:1, Engström Respirator System 300; Lab Medical AB, Bromma, Sweden).

After median sternotomy and systemic heparinization (200 U/kg), the pericardium was opened, a vent was introduced into the left ventricle through the left atrial appendage, and both caval veins were clamped. After aortic crossclamping, $1 \mathrm{~L}$ of Bretschneider's procaine containing solution No. 3 (sodium, $12 \mathrm{mmol} / \mathrm{L}$; potassium, 10 $\mathrm{mmol} / \mathrm{L}$; magnesium, $1 \mathrm{mmol} / \mathrm{L}$; procaine, $7.3 \mathrm{mmol} / \mathrm{L}$; chloride, $31.3 \mathrm{mmol} / \mathrm{L}$; and mannitol, $239 \mathrm{mmol} / \mathrm{L}$; oxygenated solution with $12.5 \mathrm{~mL}$ of $\mathrm{NaOH}$ added to obtain a $\mathrm{pH}$ of 7.4) was infused antegradely through the aortic root. After infusion, the hearts were excised and immersed in 0.5 L of cold $\left(4^{\circ} \mathrm{C}-6^{\circ} \mathrm{C}\right)$ heparinized saline solution. The hearts were kept at this temperature during a hypothermic cardioplegic storage (HCS) period of either 6 or 30 hours.

Study series. We compared hearts from control pigs with hearts from captopril-treated pigs in two distinct study series. Hearts were randomized within, but not between, study series.

In one series we studied cardiac hemodynamics and metabolism during 60 minutes of blood reperfusion subsequent to 6 hours of HCS.

Control pigs $(n=8)$. After cardioplegic arrest, hearts were excised and subjected to 6 hours of HCS. Subsequently, the hearts were reperfused with blood in a modified Langendorff model.

Captopril-treated pigs $(n=9)$. Animals were pretreated with increasing oral doses of captopril (Capoten) for 3 weeks. They received $12.5 \mathrm{mg}$ once a day on day 1 , increasing to
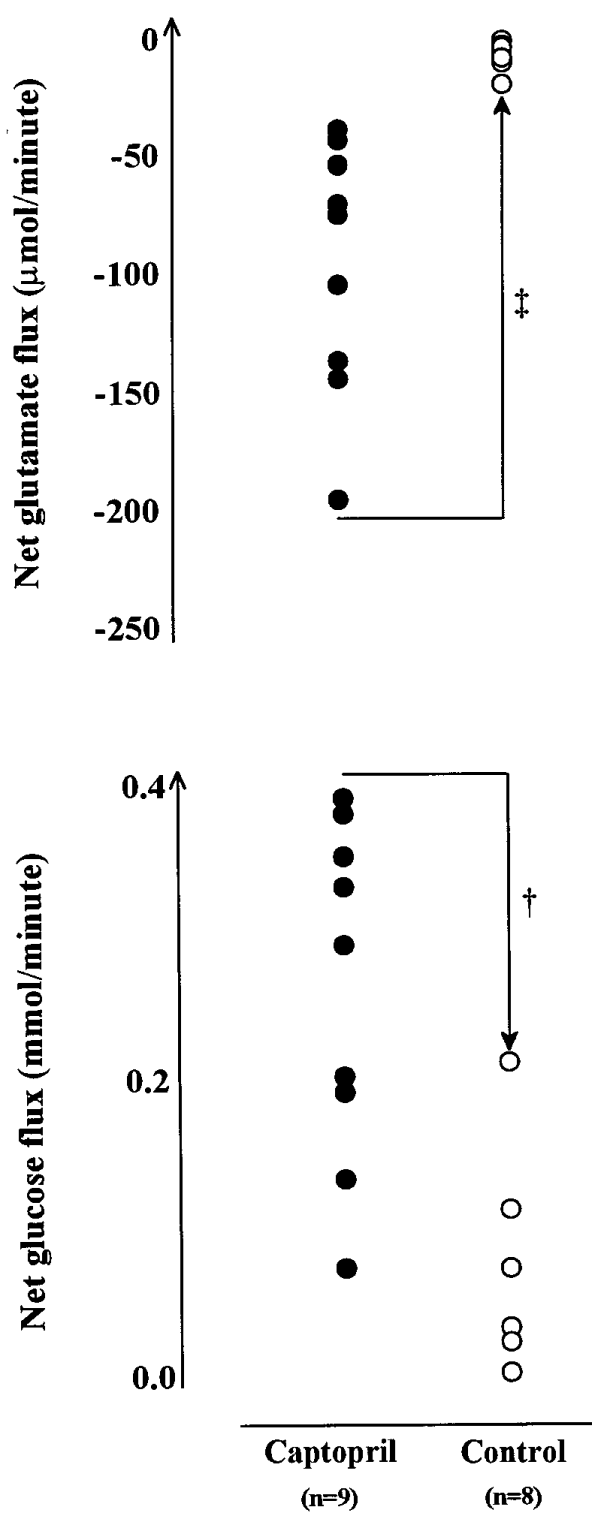

Fig 1. Net glutamate and glucose flux in captopril-treated $(\mathrm{n}=9)$ and control $(\mathrm{n}=8)$ hearts at the start of reperfusion (0 minutes). Note that the net glucose flux was $0.0 \mathrm{mmol} / \mathrm{min}$ in 3 control animals. At the start of reperfusion, captopril increased glutamate release approximately 11 -fold $(\ddagger P<$ $.001)$ and glucose uptake 5-fold $(\dagger P=.02)$.

$37.5 \mathrm{mg} 3$ times a day on day 7 , and thereafter to $50 \mathrm{mg} 3$ times daily for the remaining 2 weeks. Before the operation, an intravenous bolus of captopril $(25 \mathrm{mg})$ was given. In addition, captopril-containing $(1 \mathrm{mg} / \mathrm{L})$ cardioplegic solution was infused before exposure to 6 hours of HCS and subsequent reperfusion with captopril-containing blood $(1 \mathrm{mg} / \mathrm{L})$ in the Langendorff model. 
Table I. Blood flow and metabolic variables (net glucose, lactate, oxygen, glutamate, and alanine flux across the myocardium) in captopril-treated $(n=9)$ and control $(n=8)$ hearts during 60 minutes of blood reperfusion in a modified Langendorff model

\begin{tabular}{llcccc}
\hline & & \multicolumn{4}{c}{ Reperfusion time (min) } \\
\cline { 3 - 5 } Variable & Group & 0 & 4 & 8 & 12 \\
\hline Blood flow (L/min) & Captopril & $0.58 \pm 0.05$ & $0.57 \pm 0.06$ & $0.58 \pm 0.09$ & $0.62 \pm 0.10$ \\
& Control & $0.53 \pm 0.07$ & $0.53 \pm 0.07$ & $0.56 \pm 0.10$ & $0.63 \pm 0.11$ \\
Glucose flux (mmol/min) & Captopril & $0.25 \pm 0.12 \dagger$ & $0.04 \pm 0.03$ & $0.06 \pm 0.04$ & $0.21 \pm 0.15 *$ \\
& Control & $0.05 \pm 0.08$ & $0.04 \pm 0.05$ & $0.06 \pm 0.06$ & $0.13 \pm 0.09$ \\
Lactate flux (mmol/min) & Captopril & $-0.90 \pm 0.32$ & $-0.37 \pm 0.17$ & $-0.35 \pm 0.21$ & $-0.30 \pm 0.19$ \\
& Control & $-0.80 \pm 0.25$ & $-0.37 \pm 0.17$ & $-0.22 \pm 0.20$ & $-0.23 \pm 0.11$ \\
Oxygen flux (mL/min) & Captopril & $18.68 \pm 10.15$ & $32.61 \pm 7.42 \dagger$ & $33.39 \pm 9.35 \dagger$ & $28.96 \pm 9.21 \dagger$ \\
Glutamate flux $(\mathrm{mmol} / \mathrm{min})$ & Control & $20.48 \pm 5.56$ & $20.95 \pm 4.49$ & $22.59 \pm 6.49$ & $17.87 \pm 4.26$ \\
& Captopril & $-98.75 \pm 53.47 \ddagger$ & $-2.65 \pm 1.70$ & $-2.39 \pm 1.84$ & $-3.92 \pm 1.42$ \\
Alanine flux $(\mu \mathrm{mol} / \mathrm{min})$ & Control & $-8.69 \pm 8.05$ & $-2.23 \pm 2.24$ & $-1.59 \pm 1.27$ & $-2.31 \pm 1.98$ \\
& Captopril & $-50.62 \pm 54.96 \ddagger$ & $-5.39 \pm 2.29$ & $-5.98 \pm 3.51$ & $-6.73 \pm 1.39$ \\
\hline
\end{tabular}

Values shown are means \pm SD. $P$ values indicate differences between captopril-treated and control hearts during reperfusion. Because of nonhomogeneous data at the start of reperfusion, glutamate and alanine flux were compared from 4 minutes of reperfusion.

$* \dagger$ Significant differences during reperfusion $(* P<.05, \uparrow P<.02$; modified Bonferroni post hoc test).

$\ddagger$ Significant differences between captopril-treated and control hearts at the start of reperfusion $(P<.001$; nonparametric test $)$.

In another series we studied myocardial energy stores and metabolites during 30 hours of HCS.

Control pigs $(n=8)$. Cardioplegic arrest was induced, and the hearts were subjected to 30 hours of HCS. The hearts were not reperfused.

Captopril-treated pigs $(n=9)$. Animals were premedicated with captopril as in the previous study series, and cardioplegic arrest was induced with captopril-containing cardioplegic solution. The hearts were subjected to 30 hours of HCS without subsequent reperfusion.

\section{Reperfusion}

Hearts allocated to 6 hours of HCS and 60 minutes of reperfusion. After 6 hours of $\mathrm{HCS}$, the hearts were reperfused in a modified Langendorff perfusion model with bloodRinger chloride solution (1:1), as previously described. ${ }^{9,10}$ The hearts were prepared for reperfusion as described. ${ }^{9}$ Electrical defibrillation was performed after 10 minutes of reperfusion because of ventricular fibrillation at the beginning of reperfusion. At this time, the hearts had reached a temperature necessary to obtain regular contractions after defibrillation. Left ventricular function was monitored continuously during reperfusion, and myocardial blood flow and content of oxygen, lactate, glucose, glutamate, and alanine in arterial and coronary sinus blood were measured simultaneously at the start of reperfusion and after 4, 8, 12, 18, 25, 40, and 60 minutes of reperfusion.

Measurements. Left ventricular peak systolic pressure, end-diastolic pressure, and the first derivative of the left ventricular pressure $(\mathrm{dP} / \mathrm{dt})$ were recorded continuously during the reperfusion period. ${ }^{10}$ Developed left ventricular pressure was calculated as the difference between left ventricular peak systolic pressure and end-diastolic pressure.
Myocardial blood flow was measured directly by collecting the blood perfusate from the right atrium during reperfusion.

Lactate was analyzed in whole blood, ${ }^{11}$ and glucose, ${ }^{12}$ glutamate, and alanine ${ }^{13}$ were analyzed in plasma. Net metabolite flux across the myocardium was calculated as aorta-coronary sinus concentration differences multiplied by myocardial blood flow for whole blood analyses corrected by multiplying metabolite flux with 1 - hematocrit for plasma analyses. A negative net flux reflects release, and a positive net flux reflects uptake of a metabolite. Blood oxygen saturation and pressure were measured with a blood gas analyzer (Copenhagen ABL, Copenhagen, Denmark). Myocardial oxygen uptake (in milliliters per minute) was calculated as previously described. ${ }^{10}$

\section{Prolonged HCS}

Hearts allocated to 30 hours of HCS. During 30 hours of HCS, we harvested transmyocardial biopsy specimens from the anterior wall of the left ventricle by using a Tru-Cut biopsy needle (Baxter Healthcare Corporation, Deerfield, Ill). Samples were obtained at 15 minutes and 1, 3, 6, 12, 18, 22, 24, 27, and 30 hours of HCS.

Measurements. The tissue samples were plunged into liquid nitrogen, and metabolites were extracted by using $500 \mu \mathrm{L}$ of ice-cold $0.42 \mathrm{mmol} / \mathrm{L}$ perchloric acid. The samples were homogenized mechanically on ice-bath with a Teflon pestle and centrifuged at $4{ }^{\circ} \mathrm{C} .{ }^{14}$ Tissue concentrations of lactate, ${ }^{11}$ alanine, and glutamate ${ }^{13}$ were determined enzymatically in the clear supernatant, as described for the blood samples. High-energy phosphates were analyzed by using high-performance chromatography (Shimadzu, Kyoto, Japan). ${ }^{14}$ Tissue glycogen content was determined by using the filter paper technique. ${ }^{15}$ 


\begin{tabular}{|c|c|c|c|c|}
\hline \multicolumn{4}{|c|}{ Reperfusion time (min) } & \multirow[b]{2}{*}{$\mathrm{P}$ values (ANOVA) } \\
\hline 18 & 25 & 40 & 60 & \\
\hline $0.67 \pm 0.09$ & $0.65 \pm 0.10$ & $0.64 \pm 0.09$ & $0.64 \pm 0.10$ & .9 \\
\hline $0.65 \pm 0.10$ & $0.65 \pm 0.12$ & $0.64 \pm 0.12$ & $0.66 \pm 0.13$ & \\
\hline $0.19 \pm 0.04 *$ & $0.14 \pm 0.10^{*}$ & $0.09 \pm 0.07$ & $0.08 \pm 0.04$ & .001 \\
\hline $0.08 \pm 0.03$ & $0.04 \pm 0.06$ & $0.11 \pm 0.05$ & $0.07 \pm 0.06$ & \\
\hline$-0.05 \pm 0.16$ & $-0.05 \pm 0.18$ & $0.03 \pm 0.15$ & $0.01 \pm 0.29$ & .6 \\
\hline $0.02 \pm 0.17$ & $-0.12 \pm 0.36$ & $0.08 \pm 0.16$ & $0.06 \pm 0.21$ & \\
\hline $28.23 \pm 8.66 \dagger$ & $24.86 \pm 9.05 \dagger$ & $25.04 \pm 11.33 \dagger$ & $15.59 \pm 5.80$ & .001 \\
\hline $17.12 \pm 3.66$ & $15.97 \pm 2.79$ & $14.39 \pm 3.30$ & $11.28 \pm 1.91$ & \\
\hline$-0.88 \pm 1.71$ & $-1.17 \pm 0.99$ & $-0.56 \pm 1.64$ & $-0.83 \pm 1.39$ & .7 \\
\hline$-1.32 \pm 1.32$ & $-0.67 \pm 1.42$ & $-0.10 \pm 1.73$ & $-0.14 \pm 0.90$ & \\
\hline$-2.90 \pm 3.00$ & $-3.63 \pm 3.08$ & $-4.39 \pm 2.25$ & $-5.28 \pm 5.95$ & .9 \\
\hline$-5.15 \pm 3.65$ & $-5.75 \pm 3.42$ & $-4.84 \pm 3.20$ & $-4.33 \pm 3.59$ & \\
\hline
\end{tabular}

Statistical analysis. All results are presented as means \pm SD. Data were tested for normality and homogeneity of variance. When statistically insignificant, variables were considered unchanged or unaffected.

Hearts allocated to HCS and reperfusion. Functional variables were compared from 12 minutes of reperfusion when all hearts were beating to the end of reperfusion. Blood flow and glucose, lactate, and oxygen flux were compared from the start to the end of reperfusion. Glutamate and alanine flux were compared from 4 minutes to the end of reperfusion. We used analysis of variance (ANOVA) for repeated measurements with the BMDP computer program 5V ("unbalanced repeated-measures models with structural covariance matrices"; BMDP Software, Los Angeles, Calif). If significant, the post hoc modified $t$ test, according to the method of Bonferroni, was used to localize statistical differences. Glutamate and alanine flux at the start of reperfusion were compared by nonparametric statistics. Correlation between variables was analyzed by linear regression.

Hearts allocated to prolonged HCS. Comparisons were made over 30 hours of HCS by using ANOVA for repeated measurements.

\section{Results}

Intraoperatively, left ventricular function was similar in captopril-treated and control hearts (developed left ventricular pressure, $67 \pm 14$ vs $76 \pm 14 \mathrm{~mm} \mathrm{Hg}$, $P=.2$; contractility, $700 \pm 182$ vs $794 \pm 182 \mathrm{~mm} \mathrm{Hg} / \mathrm{s}, P$ $=.3$; relaxation, $952 \pm 337$ vs $1167 \pm 366 \mathrm{~mm} \mathrm{Hg} / \mathrm{s}, P=$ .1 ; heart rate, $78 \pm 15$ vs $80 \pm 14$ beats/min, $P=.6$ ).
Effects of captopril on myocardial function and metabolism during 60 minutes of reperfusion after 6 hours of hypothermic cardioplegic storage

Left ventricular function. Developed left ventricular pressure was increased in captopril-treated hearts during reperfusion ( $151 \pm 16$ vs $134 \pm 19 \mathrm{~mm} \mathrm{Hg}, P=.02)$. The same was the case for left ventricular relaxation $(-\mathrm{dP} / \mathrm{dt}$, $1508 \pm 383$ vs $1307 \pm 384 \mathrm{~mm} \mathrm{Hg} / \mathrm{s}, P=.04$ ), whereas captopril decreased heart rate ( $110 \pm 27$ vs 133 beats $/ \mathrm{min}$, $P=.04)$. We found no differences in rate pressure product $(16,610 \pm 1652$ vs $17,822 \pm 1827 \mathrm{~mm} \mathrm{Hg} / \mathrm{min}, P=$ .6), contractility ( $+\mathrm{dP} / \mathrm{dt}$; $1668 \pm 347$ vs $1656 \pm 346 \mathrm{~mm}$ $\mathrm{Hg} / \mathrm{s}, P=.9$ ), or left ventricular end-diastolic pressure $(11.9 \pm 3.3$ vs $11.3 \pm 3.4 \mathrm{~mm} \mathrm{Hg}, P=.8)$ between captopril-treated and control hearts during reperfusion.

Myocardial blood flow. We observed no differences in myocardial blood flow between captopril-treated hearts and control hearts during 60 minutes of reperfusion (Table I).

Glucose uptake. Glucose uptake was increased in captopril-treated hearts during reperfusion $(P<.001)$, despite similar myocardial blood flow in the two study groups (Table I). In both captopril-treated and control hearts, glucose uptake showed a characteristic biphasic pattern with a high initial uptake at the start of reperfusion followed by a decline after 4 minutes of reperfusion. This was followed by a second increase after defibrillation (12-18 minutes of reperfusion). This pattern was most pronounced in captopril-treated hearts, and the effect of captopril on glu- 
Table II. Tissue content of metabolic variables (glycogen, ATP, glutamate, and alanine) in captopril-treated $(n=9)$ and control $(n=8)$ hearts during 30 hours of HCS

\begin{tabular}{|c|c|c|c|c|c|}
\hline \multirow[b]{2}{*}{ Variable } & \multirow[b]{2}{*}{ Group } & \multicolumn{3}{|c|}{ HCS time $(h)$} & \multirow[b]{2}{*}{$\mathrm{P}$ values (ANOVA) } \\
\hline & & 0.25 & 6 & 30 & \\
\hline \multirow[t]{2}{*}{ Glycogen content (nmol/mg) } & Captopril & $29.56 \pm 4.98$ & $21.78 \pm 2.22$ & $8.78 \pm 3.73$ & .5 \\
\hline & Control & $27.71 \pm 5.28$ & $20.00 \pm 4.31$ & $9.25 \pm 3.45$ & \\
\hline \multirow[t]{2}{*}{ Lactate content (nmol/mg) } & Captopril & $1.73 \pm 2.42$ & $13.09 \pm 3.61$ & $25.53 \pm 2.91$ & .8 \\
\hline & Control & $0.71 \pm 0.70$ & $10.94 \pm 2.29$ & $25.53 \pm 2.90$ & \\
\hline \multirow[t]{2}{*}{ ATP content (nmol/mg) } & Captopril & $3.63 \pm 0.70$ & $2.70 \pm 0.61$ & $0.82 \pm 0.30$ & .5 \\
\hline & Control & $3.56 \pm 0.56$ & $2.53 \pm 0.34$ & $0.82 \pm 0.27$ & \\
\hline \multirow[t]{2}{*}{ Glutamate content (nmol/mg) } & Captopril & $3.50 \pm 0.95$ & $2.29 \pm 0.51$ & $1.39 \pm 0.35$ & .7 \\
\hline & Control & $3.28 \pm 0.54$ & $2.39 \pm 0.58$ & $1.46 \pm 0.47$ & \\
\hline \multirow[t]{2}{*}{ Alanine content (nmol/mg) } & Captopril & $0.83 \pm 0.43$ & $1.82 \pm 0.46$ & $2.59 \pm 0.65$ & .1 \\
\hline & Control & $0.45 \pm 0.45$ & $1.45 \pm 0.46$ & $2.34 \pm 0.59$ & \\
\hline
\end{tabular}

Values are shown as means \pm SD. $P$ values indicate differences between captopril-treated and control hearts during the period of HSC.

cose uptake was most pronounced at the start of reperfusion $(P=.02$; Fig 1 and Table I) and after defibrillation $(P=.04$; Table I).

Lactate release. Myocardial lactate release was unaffected by captopril during reperfusion (Table I). In both captopril-treated and control hearts, lactate release was high at the beginning of reperfusion, decreased during the first 25 minutes of reperfusion, and then ceased.

Oxygen uptake. Oxygen uptake data is shown in Table I. At the beginning of reperfusion (0 minutes), we observed no difference in oxygen uptake between captopril-treated and control hearts $(18.68 \pm 10.15$ vs $20.48 \pm 5.56 \mathrm{~mL} / \mathrm{min}, P=.3$ ). During the first $4 \mathrm{~min}-$ utes of reperfusion, however, oxygen uptake increased in captopril-treated hearts (from $18.68 \pm$ 10.15 to $32.61 \pm 7.42 \mathrm{~mL} / \mathrm{min}, P=.01$ ), whereas no increase was observed in control hearts $(20.48 \pm 5.56$ vs $20.95 \pm 4.49 \mathrm{~mL} / \mathrm{min}, P=.6$ ). During the remaining reperfusion period, the difference in oxygen uptake between captopril-treated and control hearts was maintained $(P<.001)$.

Glutamate release. Captopril increased glutamate release 11-fold at the start of reperfusion $(P<.001$; Fig 1 and Table I). Glutamate release declined in both captopril-treated and control hearts from the start to 4 minutes of reperfusion. This was most pronounced in captopril-treated hearts (captopril-treated hearts, from $98.75 \pm 53.47$ to $2.65 \pm 1.70 \mu \mathrm{mol} / \mathrm{min}[P<.001]$, vs control hearts, from $8.69 \pm 8.05$ to $2.23 \pm 2.24$ $\mu \mathrm{mol} / \mathrm{min}[P=.01])$.

Alanine release. Captopril increased alanine release 17 -fold at the start of reperfusion $(P<.001$; Table I). The release pattern was similar in the two groups, but like glutamate, the change in release from the start to 4 minutes of reperfusion was most pronounced in captopril-treated hearts.
Relation between glucose uptake and glutamate release at the start of reperfusion. In captopril-treated hearts there was a linear relationship between glutamate release and glucose uptake $(r=0.66, P=.05)$. This relationship was not observed in control hearts (Fig 2).

Other relations between glucose-related metabolites. In captopril-treated hearts a positive correlation was found between glutamate and alanine release at the start of reperfusion $(r=0.85, P=.01)$, whereas no relationship was observed between the release of lactate- and glucose-related amino acids $(r=0.27, P=.5$ for lactate vs glutamate; $r=0.58, P=.1$ for lactate vs alanine).

Effects of captopril on myocardial content of metabolites during 30 hours of HCS (Table II). We found no difference in heart weight between captopriltreated hearts and control hearts after 30 hours of HCS ( $280 \pm 31$ vs $273 \pm 16 \mathrm{~g}, P=.6)$.

Glycogen content. Captopril did not affect glycogen content during 30 hours of HCS. Myocardial levels of glycogen were high at the beginning of HCS in both captopril-treated and control hearts and declined continuously during the HCS period.

Lactate content. We found no difference in lactate accumulation between captopril-treated and control hearts. In both groups tissue levels of lactate increased during 30 hours of HCS.

Adenosine triphosphate content. Captopril had no effect on myocardial content of adenosine triphosphate during 30 hours of HCS. Tissue adenosine triphosphate content declined continuously during the HCS period.

Glutamate content. We found no differences in myocardial glutamate content between captopril-treated and control hearts. Myocardial levels of glutamate declined during 30 hours of HCS in both groups.

Alanine content. Captopril did not affect myocardial content of alanine during 30 hours of HCS. We 


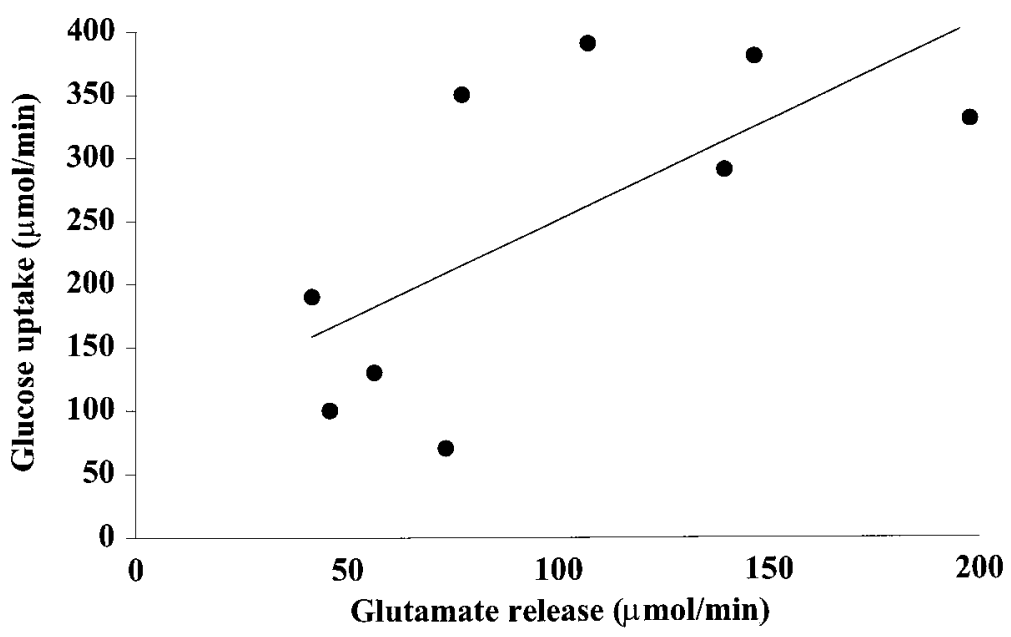

Fig 2. Correlation between glutamate release and glucose uptake in captopril-treated hearts $(\mathrm{n}=9)$ at the start of reperfusion. There was a linear relationship between the two variables in captopril-treated hearts $(r=0.66, P=$ $.05)$, which could not be found in control hearts.

observed an increase in tissue alanine content in both captopril-treated and control hearts during storage.

Relation between glucose-related amino acids. In both captopril-treated and control hearts, there was a linear relationship between tissue content of glutamate and alanine $(r=0.96, P<.001)$.

\section{Discussion}

The main finding of the present study is a captoprilinduced release of glutamate and alanine at the start of reperfusion after 6 hours of hypothermic cardioplegic storage. In addition, captopril increased glucose and oxygen uptake without influencing lactate release. Increased glutamate release and glucose uptake were most pronounced at the start of reperfusion, at which time the two variables were correlated in a linear fashion. We therefore suggest that increased glutamate release in this study is a consequence of an abrupt captopril-induced shift to oxidative glucose metabolism at the start of reperfusion after cardioplegic storage. Because we observed no differences in tissue content of glucose-related metabolites between captopril-treated and control hearts during 30 hours of HCS, the study further demonstrates that the metabolic effects of captopril are related to reperfusion rather than the cardioplegic storage.

Effects of $\mathrm{ACE}$ inhibition on functional recovery during postcardioplegic reperfusion. ACE inhibition improves the cardioprotective effects of crystalloid cardioplegic solutions. ${ }^{1,2}$ In accordance with this, ACE inhibition resulted in improved developed left ventricular pressure and relaxation during postcardioplegic reperfusion in our study. However, in contrast to previ- ous studies in isolated hearts, ${ }^{2,16,17}$ we found no effect of captopril on myocardial blood flow, indicating that the captopril-induced alterations in myocardial metabolite exchange are independent of myocardial blood flow.

Effects of ACE inhibition on glutamate and glucose metabolism during postcardioplegic reperfusion. Glutamate plays an important role for energy metabolism in the ischemic myocardium (Fig 3, A). ${ }^{18,19}$ Clinical trials demonstrating increased glutamate uptake in patients with coronary artery disease ${ }^{20,21}$ yield additional support for the importance of glutamate under conditions of ischemia. These studies showed a close relationship between myocardial carbohydrate metabolism and glutamate exchange by a positive correlation between glucose and glutamate uptake in patients with ischemic heart disease. ${ }^{21}$ In addition, we have demonstrated that glutamate enrichment during reperfusion improves postcardioplegic recovery. ${ }^{22}$ In the present study, captopril induced a massive glutamate release during postcardioplegic reperfusion. We have previously observed a substantial loss of glutamate from pig hearts at the start of reperfusion after cold crystalloid cardioplegia. ${ }^{23}$ However, the glutamate release in captopril-treated hearts increased approximately 11fold compared with that found in control hearts.

Our findings suggest that the role of glutamate for energy generating metabolism after captopril treatment is minor during reperfusion when myocardial oxygen and glucose availability is restored (Fig 3, B). We suggest that the underlying mechanism is the superiority of glucose over glutamate for replenishment of citric acid cycle intermediates when excess glucose and oxygen is 

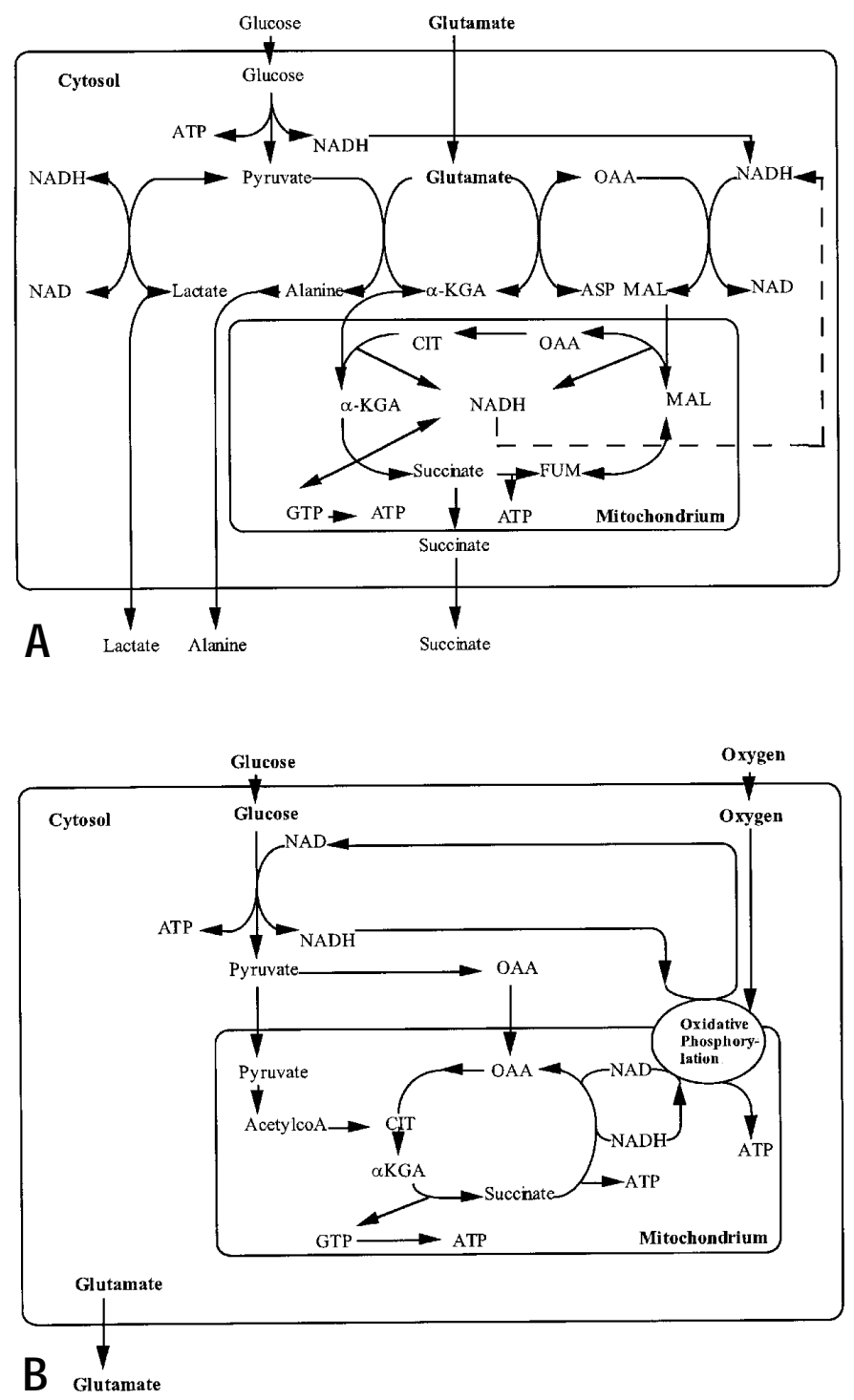

Fig 3. Schematic presentation of the coupling between glutamate metabolism, glycolysis, and reactions of the citric acid cycle, indicating the pathways of anaerobic energy formation (A), and oxidative metabolism of glucose and possible fate of glutamate under aerobic conditions (B). $\alpha-K G A$, $\alpha$-Keto-glutarate; ASP, aspartate; ATP, adenosine triphosphate; CIT, citrate; FUM, fumerate; GTP, guanosine triphosphate; $M A L$, malate; $N A D$ and $N A D H$, oxidized and reduced nicotinamide adenine dinucleotide; $O A A$, oxaloacetate.

available. The necessity of glutamate for anaplerosis of the citric acid cycle seems to cease under these conditions. This explains not only the glutamate release in captopril-treated hearts but also the linear relationship between glucose uptake and glutamate release.

Myocardial glucose uptake is enhanced up to 3-fold during reperfusion after hypoxia. ${ }^{24,25}$ Glucose is transformed to both acetyl coenzyme A and the citric acid cycle intermediate oxaloacetate (Fig 3, B) ${ }^{26}$ In captopril-treated hearts we found increased uptake of glu- cose, which supplies the citric acid cycle with both acetyl coenzyme A and oxaloacetate, enabling the heart to oxidize larger amounts of glucose. Thus the improvement in developed left ventricular pressure and relaxation seems to be caused by a captopril-induced enhancement of glucose oxidation.

Effects of captopril during prolonged cardioplegic storage. A number of substrates are converted into oxidizable intermediates during ischemia. As a consequence of anaerobic breakdown of glycogen, lactate 
accumulates and glutamate is transaminated to alanine, which also accumulates in the cytosol. ${ }^{8,27,28}$ This is in accordance with our findings of decreasing tissue content of glycogen, adenosine triphosphate, and glutamate and increasing tissue content of lactate and alanine during 30 hours of cardioplegic storage. More important, captopril had no effect on any of the measured metabolites during storage. In particular, we found no glutamate accumulation, which could explain the massive glutamate release at the start of reperfusion. The effects of captopril demonstrated in the present study are therefore strictly related to the reperfusion period. The glutamate release at the start of reperfusion in captopril-treated hearts is most likely caused by metabolic modulation, as described above.

In conclusion, the present study demonstrates that the cardioprotective properties of captopril in connection with cardioplegia and reperfusion are strictly related to the reperfusion period. The study further demonstrates that captopril increases glutamate release during reperfusion after cardioplegic storage. We suggest that this is caused by increased myocardial glucose uptake, which enhances anaplerosis of citric acid cycle intermediates and enables increased glucose oxidation in captopriltreated hearts during reperfusion.

We thank statisticians Leif Spange Mortensen (Uni-C, Aarhus, Denmark) and Niels Trolle (Department of Biostatistics, University of Aarhus, Denmark) for statistical support and Mrs Eva Sparrewath and Ms Bente Jacobsen for laboratory assistance.

\section{REFERENCES}

1. Di Pasquale P, Paterna S, Valenza M, Valdes L, Albano V, Trombino G, et al. Effects of captopril on myocardial protection during cardioplegia. Int J Cardiol 1993;42:25-30.

2. Dogan R, Sarigul A, Isbir S, Farsak B, Tuncer M, Kilinc K, et al. Beneficial effect of captopril against ischemia-reperfusion injury in isolated guinea pig hearts. Scand J Clin Lab Invest 1998;58: $119-26$.

3. Zhang X, Xie YW, Nasjletti A, Xu X, Wolin MS, Hintze TH. ACE inhibitors promote nitric oxide accumulation to modulate myocardial oxygen consumption. Circulation 1997;95:176-82.

4. Matoba S, Tatsumi T, Keira N, Kawahara A, Akashi K, Kobara $\mathrm{M}$, et al. Cardioprotective effect of angiotensin-converting enzyme inhibition against hypoxia/reoxygenation injury in cultured rat cardiac myocytes. Circulation 1999;99:817-22.

5. Rett K, Maeker E, Renn W, van Gielst W, Haering HE. Perfusionindependent effect of bradykinin and fosinoprilate on glucose transport in Langendorff rat hearts. Am J Cardiol 1997;80:143A-7A.

6. Randsbæk F, Kimose HH, Hansen SB, Jacobsen B, Bøtker HE, Nielsen TT. Captopril improves oxygen and glucose extraction in pig hearts during reperfusion after cold cardioplegic storage. Scand Cardiovasc J. In press.

7. Pisarenko OI, Baranov AV, Pomerantsev EV, Studneva IM, Pavlov NA. Myocardial metabolism of glutamate and left ven- tricular function in patients with coronary arterial disease. Int $\mathrm{J}$ Cardiol 1989;23:43-52.

8. Wiesner RJ, Deussen A, Borst M, Schrader J, Greishaber MK. Glutamate degradation in the ischemic dog heart: contribution to anaerobic energy production. J Mol Cell Cardiol 1989;21:49-59.

9. Kimose HH, Ravkilde J, Helligs $\varnothing$ P, Knudsen MA, Baandrup U. Recovery after cold cardioplegic arrest of isolated blood-perfused pig hearts excised from non-anaesthetized pigs. Eur Surg Res 1990;22:323-35.

10. Randsbæk F, Kimose HH, Hansen SB, Bøtker HE, Bagger JP, Nielsen TT. Haemodynamic and metabolic effects of gallopamil as additive to calcium-containing and calcium-free cardioplegic solutions in mature pig hearts. Scand Cardiovasc J 1997;31:83-90.

11. Hohorst HJ. L-(+)-Lactate, determination with lactate dehydrogenase and DPN. In: Bergmeyer HU, editor. Methods of enzymatic analysis. New York: Academic Press; 1963. p. 266-70.

12. Banauch D, Brümmer W, Ebeling W, Metz H, Rindfrey H, Lang $\mathrm{H}$, et al. Glucose dehydrogenase for the determination of glucose concentrations in body fluids. Z Klin Chem Klin Biochem 1975; 13:101-7.

13. Thomassen AR, Nielsen TT, Bagger JP, Henningsen P. Whole blood versus plasma measurements of glutamate and alanine across the human myocardium. Scand J Clin Lab Invest 1987;47: 293-300.

14. Bøtker HE, Helligsø P, Kimose HH, Thomassen A, Nielsen TT. Determination of high energy phosphates and glycogen in cardiac and skeletal muscle biopsies, with special reference to influence of biopsy technique and delayed freezing. Cardiovasc Res 1994;28:524-7.

15. Bøtker HE, Randsbæk F, Hansen SB, Thomassen A, Nielsen TT. Superiority of acid extractable glycogen for detection of metabolic changes during myocardial ischemia. J Mol Cell Cardiol 1995;27:1325-32.

16. Li K, Xiu C. Protective effects of captopril and enalapril on myocardial ischemia and reperfusion damage of rat. J Mol Cell Cardiol 1987;19:909-15.

17. Menasché P, Grousset C, Peynet J, Mounas C, Bloch G, Piwnica A. Pre-treatment with captopril improves myocardial recovery after cardioplegic arrest. J Cardiovasc Pharmacol 1992;19:402-7.

18. Taegtmeyer H, Ferguson AG, Lesch M. Protein degradation and amino acid metabolism in autolyzing rabbit myocardium. Exp Mol Pathol 1977;26:52-62.

19. Wiesner RJ, Kreutzer U, Rösen P, Greishaber MK. Subcellular distribution of malate-aspartate cycle intermediates during normoxia and anoxia in the heart. Biochem Biophys Acta 1988;936: 114-23.

20. Thomassen A, Nielsen TT, Bagger JP, Thuesen L. Myocardial glutamate and alanine exchange related to carbohydrate metabolism in patients with normal and stenotic coronary arteries. Clin Physiol 1984;4:425-34.

21. Thomassen A, Bagger JP, Nielsen TT, Henningesen P. Altered global myocardial substrate preference at rest and during pacing in coronary artery disease with stable angina pectoris. Am J Cardiol 1988;62:686-93.

22. Kimose HH, Helligsø P, Randsbæk F, Kim Y, Bøtker HE, Hansen $\mathrm{SB}$, et al. Improved recovery after cold crystalloid cardioplegia using low-dose glutamate enrichment during reperfusion after aortic unclamping: a study in isolated blood-perfused pig hearts. Thorac Cardiovasc Surg 1996;44:118-25.

23. Kimose HH, Ravkilde J, Helligsø P, Knudsen MA, Thomassen AR, Nielsen TT, et al. Myocardial loss of glutamate after cold 
chemical cardioplegia and storage in isolated blood-perfused pig hearts. Thorac Cardiovasc Surg 1993;41:93-100.

24. Renstrom B, Nellis SH, Leidtke AJ. Metabolic oxidation of pyruvate and lactate during early myocardial reperfusion. Circ Res 1990;66:282-8.

25. Dingelborg LM, Kinne RKH, Greishaber MK. Transport and metabolism of L-glutamate during oxygenation, anoxia, and reoxygenation of rat cardiac myocytes. Am J Physiol 1996;270: H1825-32.

26. Taegtmeyer H. Energy metabolism in the heart: from basic concepts to clinical applications. Curr Probl Cardiol 1994;19: 74-7.

27. Taegtmeyer H, Goodwin GW, Doenst T, Frazier OH. Substrate metabolism as a determinant for postischemic functional recovery of the heart. Am J Cardiol 1997;80:3A-10A.

28. Camici P, Ferrannini E, Opie LH. Myocardial metabolism in ischemic heart disease: basic principles and application to imaging by positron emission tomography. Prog Cardiovasc Dis 1989; 32:217-38.

\section{Bound volumes available to subscribers}

Bound volumes of The Journal of Thoracic and Cardiovascular Surgery are available to subscribers (only) for the 2000 issues from the Publisher, at a cost of $\$ 134.00$ for domestic, $\$ 165.85$ for Canadian, and $\$ 155.00$ for international subscribers for Vol 119 (January-June) and Vol 120 (July-December). Shipping charges are included. Each bound volume contains a subject and author index and all advertising is removed. Copies are shipped within 60 days after publication of the last issue of the volume. The binding is durable buckram with the Journal name, volume number, and year stamped in gold on the spine. Payment must accompany all orders. Contact Mosby, Inc, Subscription Services, 11830 Westline Industrial Drive, St Louis, MO 63146-3318, USA; phone 800-453-4351 or 314-453-4351.

Subscriptions must be in force to qualify. Bound volumes are not available in place of a regular Journal subscription. 